\title{
Effect of photoperiod on the breeding season of the marsupial possum Trichosurus vulpecula
}

\author{
R. T. Gemmell ${ }^{1}$, G. Gepon ${ }^{1}$ and C. Sernia ${ }^{2}$ \\ Departments of ${ }^{1}$ Anatomy and ${ }^{2}$ Physiology and Pharmacology, University of Queensland, \\ 4072 Brisbane, Queensland, Australia
}

\begin{abstract}
The production of young by three groups of eight possums, housed in a natural, a short-day (10 h light:14 $\mathrm{h}$ dark) and a long-day (14 h light:10 h dark) photoperiod was monitored for 24 months to determine the role of photoperiod on the occurrence and duration of the breeding season. Possums were housed in each of the three light regimens on 22 November. The possum has a gestation duration of 17.5 days. Removal of the newborn young leads to ovulation approximately 9 days later and birth 26 days later. Repeated removal of pouch young was used to determine the duration of the breeding season. Possums in a natural photoperiod showed two breeding seasons for the 2 year observation, from March to October of each year. Over the same 2 year period, there were three breeding periods in possums in short-day and long-day photoperiod. A comparison of the timing of the first breeding season showed that short-day photoperiod brought the breeding season forward by 2 months and long-day photoperiod delayed it by 2.5 months. The total number of months in which births occurred was the same for natural and short-day photoperiod (16 out of 24 months) and less for long-day photoperiod (11 months). Fertility in the three groups was also examined. Within each group, there was no change in fertility with consecutive seasons. However, fertility, whether expressed as births per possum per month for each breeding period or births per possum for the total observation period, was higher $(P<0.05)$ in possums in natural photoperiod (total of $9.0 \pm 1.2$ births per possum) than in short-day $(6.5 \pm 1.9$ births per possum) or long-day ( $3.8 \pm 1.2$ births per possum) photoperiod. It was concluded that photoperiod is important in the timing of breeding season, in the fertility of breeding possums and, possibly, in the duration of breeding seasons, but that it does not determine the occurrence of the breeding season.
\end{abstract}

\section{Introduction}

Although there is a wide range of eutherian mammals in which the effect of photoperiod on reproduction has been examined, similar studies have not been carried out as extensively with marsupials. The effect of photoperiod on breeding activity has been studied in the tammar wallaby (Macropus eugenii) and in Bennett's wallaby (Macropus rufogriseus). These marsupials exhibit embryonic diapause and manipulation of daylength causes the reactivation of the corpus luteum rather than stimulation of early ovulation via the hypothalamus and pituitary. Increasing or long daylength prevent reactivation, whereas decreasing or short daylength stimulate activity in the corpus luteum which in turn reactivates the development of the dormant blastocyst in the uterus of these two macropods (TyndaleBiscoe and Renfree, 1987; Loudon and Curlewis, 1987). The majority of marsupials do not incorporate embryonic diapause in their reproductive strategy. The species used in this study, the brushtail possum, Trichosurus vulpecula, does not exhibit embryonic diapause.

Received 2 September 1992.
The brushtail possum $T$, vulpecula, a member of the family Phalangeridae, is an arboreal Australian marsupial about $2 \mathrm{~kg}$ in body weight. The duration of gestation is about 17.5 days; it gives birth to one young; and lactation continues for approximately 150 days (Pilton and Sharman, 1962). If the newborn possum is removed during the breeding season, the possum will ovulate in approximately 9 days and give birth to another young in approximately 26 days (Pilton and Sharman, 1962; Gemmell et al., 1987). By repeating this process, the duration of the breeding season may be determined experimentally. The start of the breeding season of the brushtail possum varies from January in Adelaide to April in Tasmania (Lyne and Verhagen, 1957; Pilton and Sharman, 1962). The main breeding period throughout Australia is from March to June (Kerle, 1984). The role of environmental cues, such as daylength, rainfall, nutrition or temperature, in the regulation of the onset and duration of the breeding season is not known. However, photoperiod is thought to be important in the timing of the breeding season of the possum. Thus, melatonin implants and housing in short-day photoperiods have been shown to bring forward the start of the breeding season (Gemmell, 1987, 1990; Gemmell and Sernia, 1992). Possums held in a long-day photoperiod give birth 
several months after those held in the natural photoperiod (Gemmell et al., 1987). These data indicate that the possum uses decreasing photoperiod to time the onset of the breeding season. However births occur in possums held in a long-day photoperiod, indicating that photoperiod does not determine the occurrence of the breeding season.

When melatonin implants were given to male and female possums ovulation was induced (Gemmell, 1987). However, similar results were obtained when females alone received melatonin (R. T. Gemmell, unpublished data) supporting the view that the male possum can fertilize female possums throughout the year. Even though there is evidence of seasonality in the male plasma testosterone concentrations and the size of the reproductive organs, spermatozoa are always present in the testes (Gilmore, 1969; Gemmell et al., 1986).

The major aim of this study was to determine more precisely the effect of photoperiod on the timing and occurrence of breeding seasons in possums kept in natural, short-day or longday photoperiod for two years. If activation of reproduction in the possum is due to refractoriness, then continuous ovulation should occur in a long-day photoperiod. However, the presence of a circannual rhythm should lead to periods of breeding followed by anoestrus.

\section{Materials and Methods}

\section{Animals and treatments}

Twenty-four female and six adult male possums, $T$. vulpecula, were used in this study; the breeding colony was established from possums trapped in the environs of Brisbane. All possums had produced young before being placed in this study. Eight female possums were housed in a natural photoperiod. Four female possums, and one adult male, were housed in each of two fully enclosed holding yards, $9 \mathrm{~m} \times 3 \mathrm{~m} \times 2 \mathrm{~m}$, and were supplied with running water, fruit and vegetables. The major portion of these two yards was open and the possums were thus kept in a natural photoperiod. The remaining sixteen female possums were transferred from similar outside holding yards to light controlled rooms on 22 November, when the daylength was $13.34 \mathrm{~h}$. Each light controlled room was divided into two sections by a chain wire partition. In each section, $3 \mathrm{~m} \times 3 \mathrm{~m} \times 4 \mathrm{~m}$, four female possums and one male were housed and supplied with water, fruit and vegetables. Light was supplied by two 40 watt fluorescent tubes. The level of illuminance measured from light reflected from the walls was 200 ( $\pm 10, \operatorname{SEM}, n=6$ ) lux. Light levels were determined with a National Digital Lux tester (Matsushita Electric Industrial Co. Ltd, Osaka). Each room had separate air intake and exhaust ducts which were baffled to prevent light leaks. Temperature was not controlled. Lights were switched on at $07: 00 \mathrm{~h}$ and off at 17:00 h for the eight possums held in a short-day photoperiod, and at 05:00 $\mathrm{h}$ and 19:00 h for the eight held in a long-day photoperiod.

Possums were examined weekly for 24 months for the presence of young. When present, the date of birth was determined either by observing the day of birth or estimating the age from the length of the head and the total body weight according to the method described by Lyne and Verhagen (1957). All young were removed from the pouch. If a birth did not occur 50 days after removal of young from pouch, blood samples were obtained weekly for at least the next 4 weeks. The concentration of plasma progesterone was determined by radioimmunoassay. The method of collection and assaying of samples was as described by Gemmell et al. (1987).

Progesterone concentrations in plasma were determined using sheep anti-progesterone-11-hemisuccinate-bovine serum albumin (Antiserum No. 334) donated by R. I. Cox (CSIRO, Prospect, New South Wales, Australia). The anti-serum was highly specific for progesterone; the only significant crossreaction was with $11 \beta$-hydroxyprogesterone (11.9\%). The limit of the sensitivity of the assay was $25 \mathrm{pg}$ per tube and the intraand interassay coefficients of variation were $12.5 \%(n=5)$ and $14.0 \%(n=10)$, respectively. The assay buffer blank was less than $0.1 \mathrm{ng} \mathrm{ml}^{-1}$ and the efficiency of extraction was $87.0 \%$ $(n=10)$.

\section{Statistical analysis}

The data obtained were analysed by a one- or two-way analysis of variance, as appropriate. Comparisons between means were made by Dunnet's or Newman-Keul's multiple comparison tests. Group data were expressed as means \pm SEM. The presence of seasonality in fertility was tested by applying an additive forecasting method used in predicting trends and seasonality from periodic data (Thomopoulos, 1980). This method gives an estimate of the duration of the seasonal cycle and a regression coefficient $\left(R^{2}\right)$ for the goodness-of-fit of the predicted actual data. The statistical significance of $R^{2}$ is then tested by a t test. This forecasting technique is incorporated in a commercial statistical package (NCSS package, Kaysville, Utah) which was used in the analysis of our data.

\section{Results}

The eight possums placed in a natural photoperiod gave birth from March to October over the experimental period of two consecutive years. All possums produced 2-7 young per breeding season, with peak production in April to June and a total of 38 and 23 births for the two consecutive years, respectively (Fig. 1a). The fewer births in the second year were due to a decreasing number of live possums and not to a decrease in fertility (Fig. 1b). In the months in which births occurred, the mean numbers of births per possum per month for the consecutive breeding seasons were $0.69 \pm 0.11$ (SEM) and $0.58 \pm 0.11$, respectively $(P>0.05)$.

In the short-daylength photoperiod ( $10 \mathrm{~h}$ light: $14 \mathrm{~h}$ dark), three distinct breeding periods were observed. The first breeding period was in January to August, with a peak in March, followed by shorter periods in November to February and August to November of the following year (Fig. 2a). Fertility was similar for all three breeding periods $(0.43 \pm 0.06 ; 0.34 \pm$ 0.1 and $0.44 \pm 0.11$ births per possum per month, respectively; Fig. 2b).

In the long-daylength photoperiod ( $14 \mathrm{~h}$ light:10 $\mathrm{h}$ dark), there was only one distinct breeding period from May to August followed by births in December, March, June, July and 

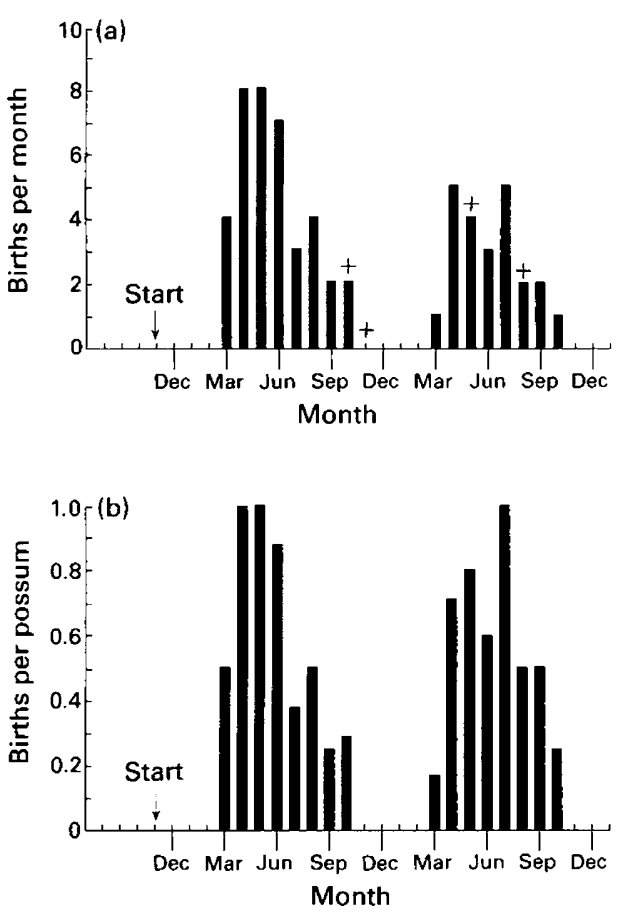

Fig. 1. (a) Births and (b) mean fertility of eight possums housed in a natural photoperiod for 24 months. $(+)$ indicates the death of a possum.
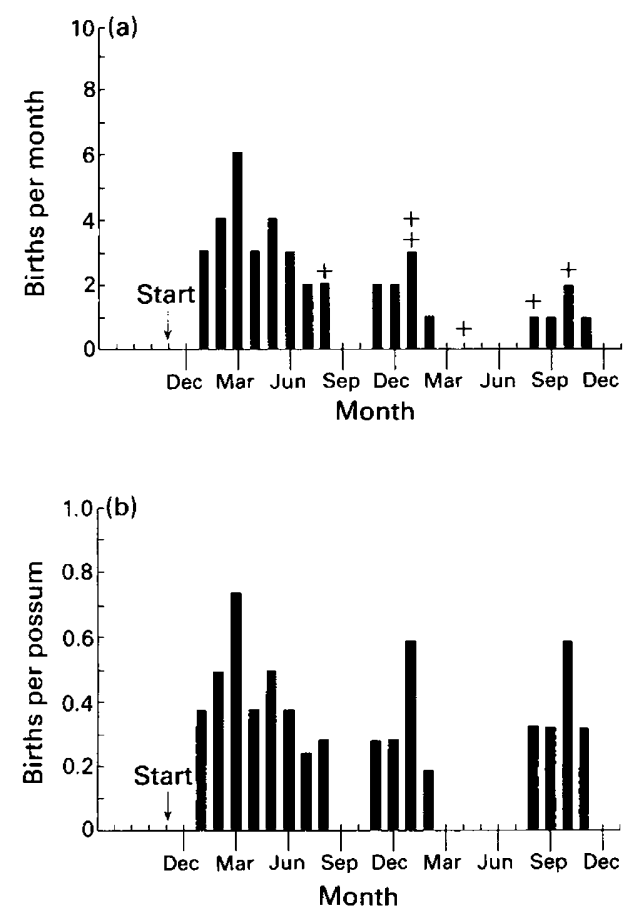

Fig. 2. (a) Births and (b) mean fertility of eight possums housed in a short-day photoperiod (10 h light:14 h dark) for 24 months. (t) indicates the death of a possum.
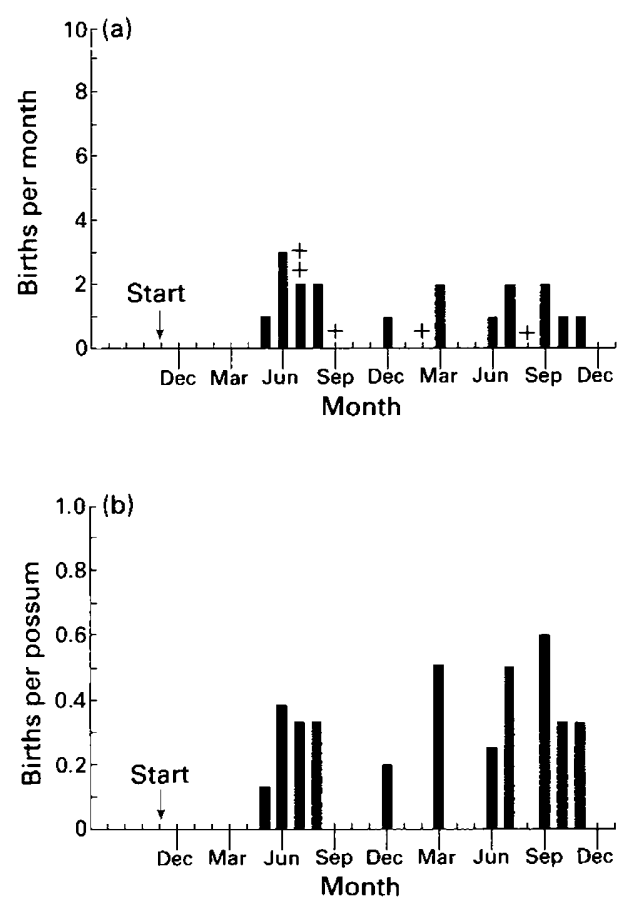

Fig. 3. (a) Births and (b) the mean fertility of eight possums housed in a long-day photoperiod ( $14 \mathrm{~h}$ light:10 $\mathrm{h}$ dark) for 24 months. (+) indicates the death of a possum.

September to November (Fig. 3a). In the first breeding period, $0.29 \pm 0.06$ births per possum per month were recorded compared with $0.40 \pm 0.06$ births per possum per month $(P>0.05)$ in the remaining months in which births occurred (Fig. 3b).

The breeding pattern of the three experimental groups was analysed for seasonality using a forecasting statistical technique (Fig. 4). Seasonality was found in all three groups, and the best fit of the predicted to the actual data (indicated by the value of $\left.R^{2}\right)$ occurred in natural daylength $\left(R^{2}=0.875 ; P<0.001\right)$ followed by that for short daylength $\left(R^{2}=0.690 ; P<0.001\right)$ and for long daylength $\left(R^{2}=0.527 ; P<0.01\right)$. The periodicity of the breeding cycle was 12 months for natural and long daylengths (peaks in June-July) and 9 months for short daylength (consecutive peaks in April, January, October). However, a less satisfactory fit $\left(R^{2}=0.426 ; P<0.05\right)$ with a periodicity of 8 months was also found for the long-daylength group.

The possibility of a shift in the time of the first breeding season was examined by comparing the time and number of births which occurred from November to the following October. For the purposes of analysis, births per possum were expressed as a percentage of the total number of births in the first breeding season. Where a possum died before the end of the season, fertility was estimated on their performance before death. An ANOVA of the data showed the first breeding season to have been delayed 2.5 months in the long-daylength photoperiod and brought forward by 2 months in short-daylength photoperiod $(P<0.05)$. The progressive number of deaths over the 2 year experimental period prevented any meaningful analysis beyond the first breeding season.

Fertility in the three experimental groups was also examined statistically. In the natural daylength, births occurred in 16 


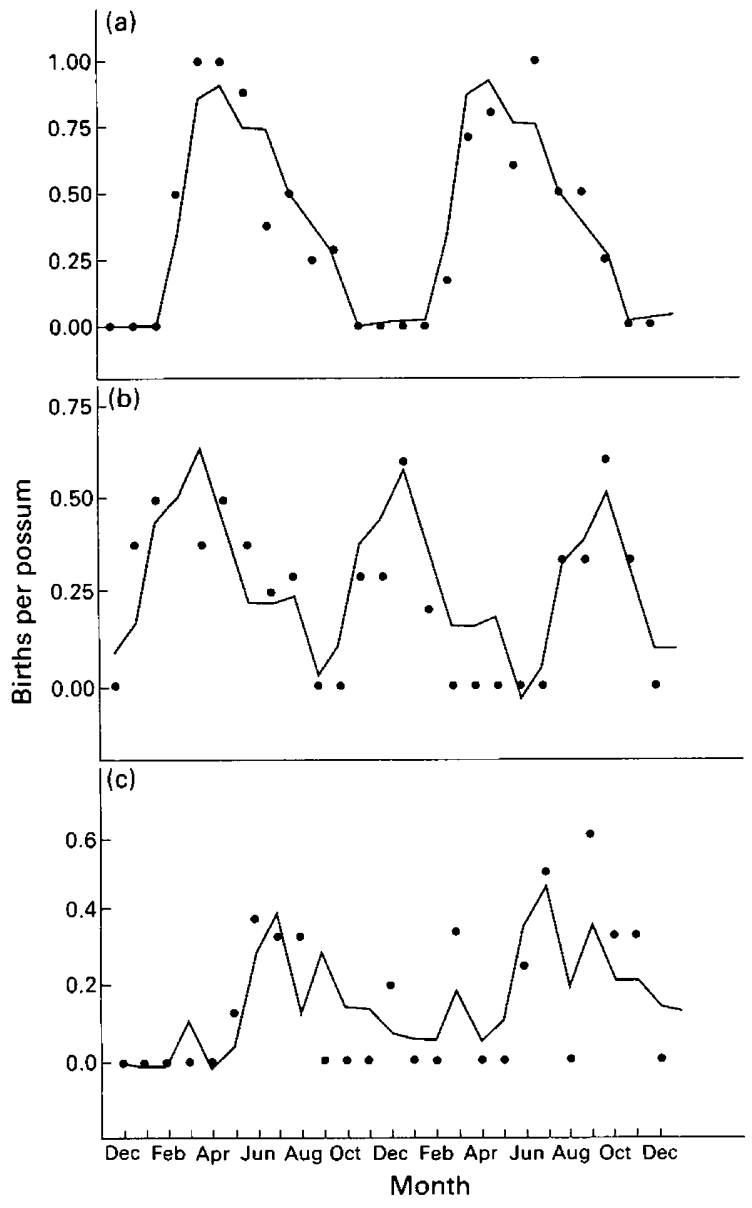

Fig. 4. The presence of seasonality in the breeding of possums in (a) natural, (b) short-day and (c) long-day photoperiod. An additive forecasting method for determining seasonality was used to fit a predicted seasonal cycle (solid line) with actual data in points $(0)$. The goodnessof -fit is indicated by the $R^{2}$ values $0.875,0.690$ and 0.527 for (a), (b) and (c), respectively. A periodicity of 12 months was present in natural and long-daylength, and 9 months in short-daylength.

months at a frequency of $0.6 \pm 0.07$ births per possum; in short daylength $0.39 \pm 0.04$ births per possum in 16 months, and in long daylength $0.34 \pm 0.04$ births per possum in 11 months. In this comparison, fertility was higher in natural daylight than in either short or long daylength $(P<0.05$; Dunnet's multiple comparison test). Since the months in which births occurred were not equal in number for the three groups, the fertility of each possum over the total 2 year experimental period was compared. Where a possum died before the end of the experiment, the overall fertility was predicted from performance before death. Over the whole experimental period, a mean of $9.0 \pm 1.2,6.5 \pm 1.9$ and $3.8 \pm 1.2$ births per possum $(n=8)$ was estimated for the natural, short and long daylength, respectively. The differences for the natural and long daylength were significant $(P<0.05$; Dunnet's multiple comparison test).

Possums that died during the course of this study did so from natural causes. The use of parous females for our study meant that some would reach the end of their expected lifespan in captivity of about four years during the course of the 2 year experimental period. Where possums had not produced young for 50 days, the presence of anoestrus was checked by measuring concentration of progesterone in plasma for the subsequent 4-6 weeks. In all cases a concentration below $1 \mathrm{ng}$ $\mathrm{ml}^{-1}$ was measured, indicating that the possums had entered anoestrus.

\section{Discussion}

Brushtail possums continued to show a seasonality in their breeding pattern when transferred from a natural to a short-day or a long-day photoperiod. All possums housed in a natural photoperiod showed a definite season for the production of young; births were observed over 8 months of the year. Possums held in a short-day or long-day photoperiod also showed periods of breeding activity followed by periods of anoestrus. Whereas the possums held in a natural photoperiod displayed two definite breeding seasons with a periodicity of 12 months over the two years of study, the possums held in the short-day photoperiod showed three shorter cycles of breeding activity with a periodicity of 9 months. A weaker, but significant 12 months breeding cycle was found in the long-day photoperiod.

In addition to a difference in the number of breeding periods, a change to a continuous photoperiod affected the timing of the breeding period. A short daylength shifted the breeding period forward, whereas long daylength delayed it. Over the 2 year study, the fertility of possums held in a natural photoperiod was greater than that of possums held in a short-day or a long-day photoperiod; the number of births per possum was 6.5 and 3.8, respectively.

The species used extensively to study short daylength breeding in eutherian mammals is sheep (Legan and Karsch, 1980; Wayne et al., 1988). In this species, refractoriness to inhibitory long-day photoperiods was thought to initiate the breeding season (Robinson and Karsch, 1985) and refractoriness to stimulatory short-day photoperiods to inhibit breeding activity (Robinson and Karsch, 1984). In a constant short-day photoperiod, ovulation was stimulated (Legan and Karsch, 1980; Wayne $e t$ al., 1988) and a circannual breeding cycle was established when this photoperiod was maintained over several years (Robinson and Karsch, 1988; Karsch et al., 1989). On the basis of these observations, Robinson and Karsch (1988) modified their previous view and stated that the role of photoperiod in timing the breeding season of ewes was to synchronize an endogenous rhythm, rather than to generate this rhythm (Robinson, 1990). This modified view was supported by two further studies. Ewes placed in an equatorial light regimen showed oestrous cycles throughout the year at variable intervals rather than in distinct breeding seasons (Jackson et al., 1990). In addition, Karsch et al. (1989) observed that ewes housed in a constant short-day photoperiod continued to show cycles of oestrus and anoestrus, although these were not synchronized without changing photoperiodic input.

The data from the present study indicate that there are similarities between the control of the breeding season of possum and that of sheep. Thus, photoperiod influences the timing of the breeding season of the possum but is not solely responsible for the induction of breeding. The short period of breeding 
activity in the possums held in a constant photoperiod compared with animals exposed to natural lighting suggests that a changing photoperiod may be required to sustain a longer period of breeding. The synchronous start to the breeding season of the possum (Gemmell, 1987, 1990; Gemmell et al, 1987; Gemmell and Sernia, 1992) supports the view that changing daylength initiates breeding activity. However, the variation in the duration of the breeding season of individual possums suggests that photoperiod does not terminate the breeding season by actively inhibiting ovulation. Malpaux and Karsch (1990) reported that a shortening daylength is required to sustain the breeding season of the sheep held in natural conditions. The present study has shown that possums, after being transferred from natural to constant short-days, have a similar duration of breeding season in the first season but the subsequent season is very much shortened. Thus, a shortening daylength may be required to sustain the breeding season of the brushtail possum, as in the sheep. In conclusion, photoperiod is important in the timing but not in the occurrence of the breeding season and may have a role in determining the duration of the annual breeding season of the possum.

The effect of photoperiod on the breeding season of marsupials has mainly been examined in two wallabies, the Bennett's (Macropus rufogriseus) and the tammar (Macropus eugenii) wallaby. Both marsupials exhibit seasonal embryonic diapause (Berger, 1966; Merchant and Calaby, 1981). The breeding season of both species occurs soon after the summer solstice. Births occur as the days shorten and continue during the first half of the year. Birth is followed by oestrus and the resultant conceptus develops up to the blastocyst stage. During the breeding season, the suckling stimulus of the pouch young inhibits the growth and implantation of the blastocyst. This is known as lactational quiescence. The removal or loss of the pouch young during the breeding season reactivates the quiescent corpus luteum and pregnancy proceeds, birth occurring 27 days later. If the removal or loss of young occurs in the latter half of the year, the corpus luteum and blastocyst remain quiescent and this is known as seasonal quiescence.

Transfer from a long- to a short-day photoperiod terminates seasonal quiescence (Sadlier and Tyndale-Biscoe, 1977; Hinds and Ottolander, 1983), as do melatonin injections or implants (Loudon $e^{t}$ al., 1985; Curlewis and Loudon, 1989). After prolonged exposure to long days, both the tammar (Sadlier and Tyndale-Biscoe, 1977) and Bennett's wallaby (Curlewis and Loudon, 1989) commence breeding. Curlewis and Loudon (1989) suggested that the initiation of the breeding season for wallabies may be due to refractoriness to long days. The inhibitory effect of long days no longer inhibited the reproductive system, and ovulation and pregnancy occurred.

A similar refractoriness to short days was suggested to terminate breeding in Bennett's wallaby. Loudon and Curlewis (1987) reported that wallabies were refractory to melatonin when this hormone was presented early in seasonal quiescence. Pregnancy did not restart after melatonin treatment because the reproductive system was in a refractory condition. They suggested that this refractory response to melatonin or short days may be the cause of the transition from lactational to seasonal quiescence.

On the basis of relatively short-term experiments showing that in the absence of a changing photoperiodic signal Bennett's wallaby became a continuous breeder, Loudon and Curlewis (1989) stated that there was little evidence for the operation of a circannual rhythm of reproduction in wallabies, and photoperiod was the major environmental control of seasonal breeding in Bennett's wallabies.

Tyndale-Biscoe and Hinds (1990) did not concur with the view expressed by Loudon and Curlewis (1989) that photorefractoriness to long days was the factor initiating breeding in wallabies. These authors focused on the importance of the corpus luteum in the reactivation of embryonic diapause and completion of pregnancy (Tyndale-Biscoe et al., 1986). During lactational quiescence the sucking of the young inhibits the development of the corpus luteum, and, consequently, the blastocyst, by eliciting pulses of prolactin with a period of less than $72 \mathrm{~h}$ that in turn maintain the corpus luteum quiescent (Tyndale-Biscoe and Hawkins, 1977; Tyndale-Biscoe and Hinds, 1990). During seasonal quiescence, increasing daylength replaces the sucking of the young as the stimulus for prolactin secretion. At the approach of the summer solstice the frequency and amplitude of prolactin pulses decreases, followed by reactivation of the blastocyst. Tyndale-Biscoe and Hinds (1990) were of the view that changing photoperiod was the cause of the decrease in prolactin secretion rather than a refractoriness to long days.

The initiation of breeding in tammar wallabies after the summer solstice is highly synchronized (Tyndale-Biscoe et al., 1986). The factors involved in this synchrony seem to be the existence of a circannual rhythm which is synchronized by photoperiod. The evidence for a circannual rhythm comes largely from two studies. In the first study tammars held in long daylengths from the equinox to the summer solstice gave birth at the same time as animals held in natural photoperiods (Sadlier and Tyndale-Biscoe, 1977). In a later study, pinealectomized tammars were shown to display seasonal breeding several years after the operation (Tyndale-Biscoe et al., 1986). Evidence that photoperiod synchronizes an endogenous circannual rhythm of reproduction has also been found in dasyurid marsupials (Dickman, 1985).

In summary, there are two main hypotheses for the control of seasonal breeding in marsupials with embryonic diapause. The first indicates that seasonality is controlled by photoperiod and driven by photorefractoriness. The second hypothesis is that seasonality results from a circannual rhythm with photoperiod providing a fine adjustment to the timing of the breeding season. This study of the possum, a marsupial that does not possess embryonic diapause, supports the latter view of the control of seasonal breeding.

The authors thank the Australian Research Council for financial assistance.

\section{References}

Berger PJ (1966) Eleven-month 'embryonic diapause' in a marsupial Nature 211 $435-438$

Curlewis JD and Loudon ASI (1989) The role of refractoriness to long daylength in the annual reproductive cycle of the female Bennett's wallaby (Macropus rufogriseus rufogriseus) Journal of Experimental Zoology 252 200-206

Dickman CR (1985) Effects of photoperiod and endogenous control on timing of reproduction in the marsupial genus Antechinus journal of Zoology, London $206509-524$ 
Gemmell RT (1987) The effect of melatonin and the removal of pouch young on the seasonality of births in the marsupial possum, Trichosurus vulpecula journal of Reproduction and Fertility $\mathbf{8 0} 301-307$

Gemmell RT (1990) The influence of daylength on the initiation of the breeding season of the marsupial possum Trichosurus vulpecula Journal of Reproduction and Fertility $88605-609$

Gemmell RT and Sernia C (1992) The role of photoperiod on the initiation of the breeding season of the possum, Trichosurus vulpecula Journal of Reproduction and Fertility 95 701-708

Gemmell RT, Cepon G and Barnes A (1986) Weekly variations in body weight and plasma testosterone concentrations in the captive male possum, Trichosurus vulpecula General and Comparative Endocrinology 62 1-7

Gemmell RT, Hughes RL and Jenkin G (1987) Comparative studies on the hormonal profiles of progesterone and prostaglandin $\mathrm{F}$ metabolite in the possum Trichosurus vulpecula. In Possums and Opossums, Studies in Evolution pp 279-291 Ed. M. Archer. Royal Zoological Society of New South Wales Surrey Beatty Sons, Sydney

Gilmore DP (1969) Seasonal reproductive periodicity in the male brush-tail possum (Trichosurus vulpecula) Joumal of Zoology 157 75-98

Hinds LA and den Ottolander RC (1983) Effect of changing photoperiod on peripheral plasma prolactin and progesterone concentrations in the tammar wallaby (Macropus engenii) Journal of Reproduction and Fertility $69631-639$

Jackson GL, Jansen H and Kao C (1990) Continuous exposure of Suffolk ewes to an equatorial photoperiod disrupts expression of the annual breeding season Biology of Reproduction 42 63-73

Karsch FJ, Robinson JE. Woodfill CII and Brown MB (1989) Cirannual cycles of luteinizing hormone and prolactin secretion in ewes during prolonged exposure to a fixed photoperiod: evidence for an endogenous reproductive rhythm Biology of Reproduction 41 1034-1046

Kerle JA (1984) Variation in the ecology of Trichosurus: its adaptive significance. In Possums and Gliders pp 115-128 Eds A Smith and I Hume. Australian Mammal Society, Surrey Beatty \& Sons, Sydney

Legan SJ and Karsch FJ (1980) Photoperiodic control of seasonal breeding in ewes: modulation of the negative feedback action of estradiol Biology of Reproduction 23 1061-1068

Loudon ASI and Curlewis JD (1987) Refractoriness to melatonin and short daylengths in early seasonal quiescence in the Bennett's wallaby (Macropus rufogriseus rufogriseus) Joumal of Reproduction and Fertility 81 543-552

Loudon ASI and Curlewis JD (1989) Evidence that the seasonally breeding Bennett's wallaby (Macropus rufogriseus rufogriseus) does not exhibit short-day photorefractoriness Joumal of Reproduction and Fertility $87641-648$

Loudon ASI, Curlewis JD and English J (1985) The effect of melatonin on the seasonal embryonic diapause of the Bennett's wallaby (Macropus rufogriseus rufogriseus) Joumal of Zoology, London 206 35-39
Lyne AG and Verhagen AMW (1957) Growth of the marsupial Trichosurus vulpecula and a comparison with some higher mammals Growth 21 167-195

Malpaux B and Karsch FJ (1990) A role for short days in sustaining seasonal reproductive activity in the ewe Joumal of Reproduction and Fertility 90 $555-562$

Merchant JC and Calaby JH (1981) Reproductive biology of the red-necked wallaby (Macropus rufogriseus banksianus) and Bennett's wallaby (M.r. rufogriseus) in captivity jourmal of Zoology, London 194 203-217

Pilton PE and Sharman GB (1962) Reproduction in the marsupial Trichosurus vulpecula journal of Endocrinology 25 119-136

Robinson JE (1990) Endogenous rhythms of luteinising hormone secretion in the ewe and their entrainment by photoperiod Progress in Comparative Endocrinology 342 653-658

Robinson JE and Karsch FJ (1984) Refractoriness to inductive day length terminates the breeding season of the Suffolk ewe Biology of Reproduction 31 $656-663$

Robinson JE and Karsch FJ (1985) Refractoriness to inhibitory day lengths initiates the breeding season of the Suffolk ewe Biology of Reproduction 32 $1024-1030$

Robinson JE and Karsch FJ (1988) Timing the breeding season of the ewe: what is the role of daylength? Reproduction, Nutrition and Development $\mathbf{2 8 ( 2 \mathbf { b } )}$ 365-374

Sadlier RMF and Tyndale-Biscoe CH (1977) Photoperiod and the termination of embryonic diapause in the marsupial Macropus engenii Biology of Reproduction 15 605-608

Thomopulos NT (1980) Applied Forecasting Methods. Prentice-Hall Inc. Englewood Cliffs, N]

Tyndale-Biscoe CH and Hawkins J (1977) The corpora lutea of marsupials: aspects of function and control. In Reproduction and Evolution pp 245-252 Eds JH Calaby and $\mathrm{CH}$ Tyndale-Biscoe. Australian Academy of Science, Canberra

Tyndale-Biscoe CH and Hinds LA (1990) Control of seasonal reproduction in the tammar and Bennett's wallabies Progress in Comparative Endocrinology 342 659-667

Tyndale-Biscoe CH and Renfree M (1987) Reproductive Physiology of Marsupials. Cambridge University Press, Cambridge, UK

Tyndale-Biscoe CH, Hinds LA and McConnell SJ (1986) Seasonal breeding in a marsupial: opportunities of a new species for an old problem Recent Progress in Hormone Research 42 471-512

Wayne NL, Malpaux B and Karsch FJ (1988) How does melatonin code for daylength in the ewe: duration of nocturnal melatonin release or coincidence of melatonin with a light-entrained sensitive period? Biology of Reproduction 39 66-75 